\title{
The Secret Life of America's Poison Centers
}

\author{
Richard C. Dart, MD, PhD \\ From the Rocky Mountain Poison and Drug Center, Denver Health, Denver, CO, and the University of Colorado, Department of Emergency \\ Medicine, Denver, co
}

0196-0644/\$-see front matter

Copyright (c) 2011 by the American College of Emergency Physicians.

doi:10.1016/j.annemergmed.2011.11.017

\section{SEE RELATED ARTICLE, P. 56.}

[Ann Emerg Med. 2012;59:62-66.]

In 1982, I was a postgraduate year 2 internal medicine resident at Albany Medical Center. Intrigued by the specialty of emergency medicine, I selected a rotation in the pediatric emergency department (ED). In the first hour of my first day, a red rotary-dial wall telephone rang. The nurse pointed to me and then the telephone-suddenly I was the poison center!

Most emergency physicians were raised in the era of poison centers. The first one was established in Chicago in 1953. The concept caught fire. Perhaps fueled by the baby boom, the number of self-identified poison centers skyrocketed to more than 600 in the United States by $1970 .{ }^{1}$ Although the rapid adoption was gratifying, these were mainly small centers that focused on their hospital's catchment area. Some were mainly a tool intended to capture pediatric patients for the hospital. Despite the large number of centers, coverage of the United States was incomplete.

The services provided by these centers varied widely. Few centers were open 24 hours; some were open only when an interested physician was on duty in the hospital. In places in which physicians were actually involved in the center, they were often like me, house officers without poisoning expertise. There was no uniform information source for unusual and complicated poisons.

\section{NOT YOUR PARENTS' POISON CENTER}

The story is much different today. In 1958, the American Association of Poison Control Centers was created to represent poison centers and reduce the toll of poisoning. Today there are 57 centers covering the entire United States. All but 3 meet the rigorous accreditation criteria of the American Association of Poison Control Centers. Among many other requirements, accredited centers are required to maintain a staff trained and current in toxicology. These nurse and pharmacist "specialists in poison information" must pass a national certification exam every 7 years. In addition, each poison center is reviewed every 5 years with explicit accreditation criteria. Every center must have trained staff responding to inquiries 24 hours a day. They must demonstrate adequate participation by 1 or more board-certified medical toxicologists. All centers use electronic medical records with standard data collection fields that are automatically uploaded to the National Poison Data System every few minutes.

In the past, poison centers were viewed primarily as a place to call for pediatric poisonings. Many poison centers were hosted in children's hospitals, and many of the original poison center directors were pediatricians. One of the important success stories of public health in America is the war on poisoning in children. Child-resistant containers, the use of imprint codes on tablets, regulatory removals of some products, widespread education, and the immediate availability of skilled advice have improved poisoning outcomes dramatically. In 1972, poisoning caused at least 216 child deaths in the United States. Although the US population increased through 2007, the number of pediatric poisoning deaths decreased by $82 \%$, to 39 deaths (Figure 1). ${ }^{2}$

Although pediatric poisonings used to dominate the call volume of poison centers, today only 52\% involve children younger than 6 years. Poisoning types that have experienced large increases include substance abuse of licit drugs such as opioid analgesics, occupational exposures, and attempted selfharm, but almost every category has experienced large increases as the call volume has increased. In 1983, the system managed 251,000 calls about poisoning exposure. ${ }^{3}$ Today, the system receives more than 2.3 million calls per year for exposures and another 1.9 million calls for information. ${ }^{4}$

Poison centers are extraordinarily cost-effective. Numerous studies have documented how the centers reduce health care costs by allowing a concerned patient to be managed at home and by advising health care providers on management of poisoned patients who do reach the hospital. ${ }^{5}$ An independent study funded by the Maternal and Child Health Bureau of the US Department of Health and Human Services found that poison centers saved $\$ 7.00$ in health care spending for every dollar of support that a poison center received. ${ }^{6}$ This calculation was based solely on ED costs and did not account for other benefits of poison centers such as shorter hospital stays and poison prevention efforts.

The development of the poison center system in the United States stands in contrast to that in most others countries. Western Europe, Australia, and New Zealand have created effective systems for individual countries. Unfortunately, many systems are limited to receiving calls only from health care professionals. Although this supports the important goal of 
Pediatric Poisoning from 1972 to 2007

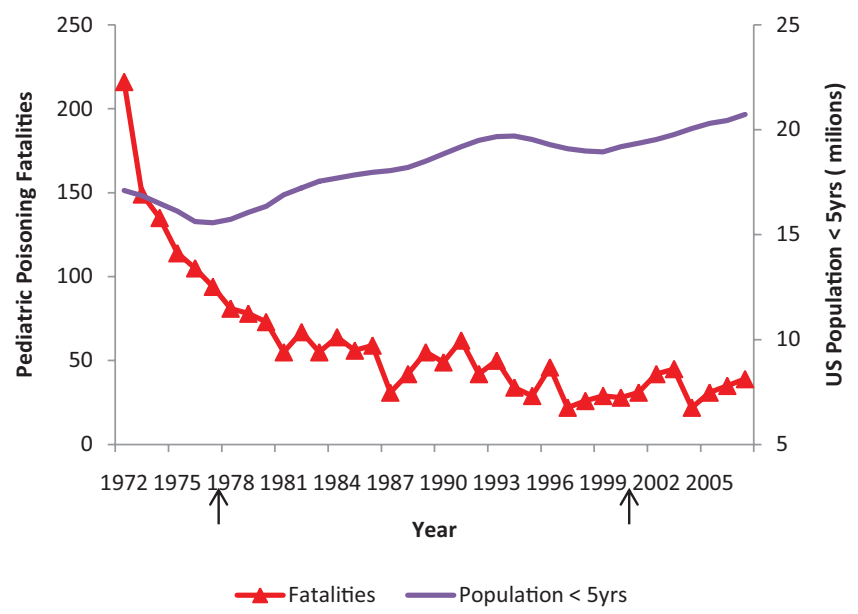

Figure 1. Pediatric poisoning fatalities compared with the total number of children younger than 5 years, 1972 to 2007. Arrows indicate deaths coded under International Classification of Diseases (ICD), Eighth Revision to deaths coded with ICD, Ninth Revision (ICD-9) in 1979 and a similar switch from ICD-9 to ICD, 10th Revision in 1999. Data were derived from National Center for Health Statistics. Adapted from O'Brien. ${ }^{2}$

improving patient care in the hospital, it omits the tremendous value of triaging calls from the public. In the United States, more than $85 \%$ of callers from the home receive care only in the home.

Far more prevalent are underdeveloped but promising poison center efforts in a variety of countries. Often, these centers are staffed by a small, dedicated, and highly motivated physician or two who can't possibly provide continuous coverage or meet the national demand for poisoning advice. Although these efforts can't match the demand for service, they do establish a foothold for further development. Ironically, countries with the worst conditions of poisoning tend to have the least developed poison center systems.

\section{A NATIONAL NETWORK OF HEALTH CARE PROFESSIONALS}

US poison centers comprise a remarkable nationwide medical call system. A single toll-free telephone number immediately leads a caller to a specialist in poison information anywhere in the United States at any time, day or night (Figure 2). A board-certified toxicologist can be reached within a few moments. This remarkable system is maintained by the voluntary cooperation of the 57 member organizations of the American Association of Poison Control Centers.

The network has proven remarkably effective in detecting new outbreaks of myriad poisonings (Table). Examples include fentanyl-contaminated heroin, lead in a variety of products produced in China, many incidents of food poisoning, and cyanide-laced acetaminophen. Often, just a few cases are sufficient for poison centers to raise the alarm to local, state, and federal health organizations.

Poison centers have expanded beyond their traditional role of providing advice about acute poisoning. Beginning far before the September 11, 2001, tragedy, poison centers were actively involved in local, state, and federal planning for management of mass casualties. Health departments have used the system to collect data on a wide range of events, including rabies, food poisoning, and Health Emergency Lines for the Public that can rapidly accommodate incidents such as outbreaks of influenza, water contamination, or hepatitis or questions about health effects of radiation in the United States after the Japanese reactor meltdown in 2011. In some states, poison centers played a pivotal role in the response to $\mathrm{H} 1 \mathrm{~N} 1$ influenza. The Florida Department of Health and the Florida Poison Information Center Network were recognized by their state for reduced H1N1-related ED costs (personal communication, Jay Schauben, Florida Poison Information Center-Jacksonville, University of Florida, November 2011). Recently, poison centers prepared for calls associated with Hurricane Irene. A significant cause of death associated with hurricanes is carbon monoxide poisoning from gasoline and kerosene generators.

In short, poison centers have matured from small local hospital-based entities to government-funded medical call centers that manage a variety of toxic and environmental incidents. Poison exposures still account for most calls, but the definition of a poison has been expanded to include hepatitis, food- or water-borne infectious agents, radiation, substances of abuse, and many others.

\section{USING POISON CENTER DATA FOR NATIONAL PUBLIC HEALTH SURVEILLANCE}

The availability of a national medical call center system offers fascinating possibilities in public health. The article by Wolkin et $\mathrm{al}^{12}$ in this issue of Annals is an excellent example of longterm efforts to develop and use the nation's poison centers. In conjunction with the Centers for Disease Control and Prevention (CDC) (Health Studies Branch, Division of Environmental Hazards and Health Effects, National Center for Environmental Health), major effort has been expended in developing the poison center call system and the software needed to meet the surveillance needs of our national preparedness and security plans.

Poison center data from all poison centers are uploaded automatically every few minutes into the National Poison Data System. If these data exceed specific thresholds for call volume or a constellation of findings (case-based surveillance) an alert goes to a group of toxicologists and epidemiologists from the CDC and American Association of Poison Control Centers to determine its public health significance. Wolkin et $\mathrm{l}^{12}$ illustrate how this information can be used to anticipate new cases and speed recognition as an outbreak spreads. In the past, such efforts were slow and the result was to simply document and 


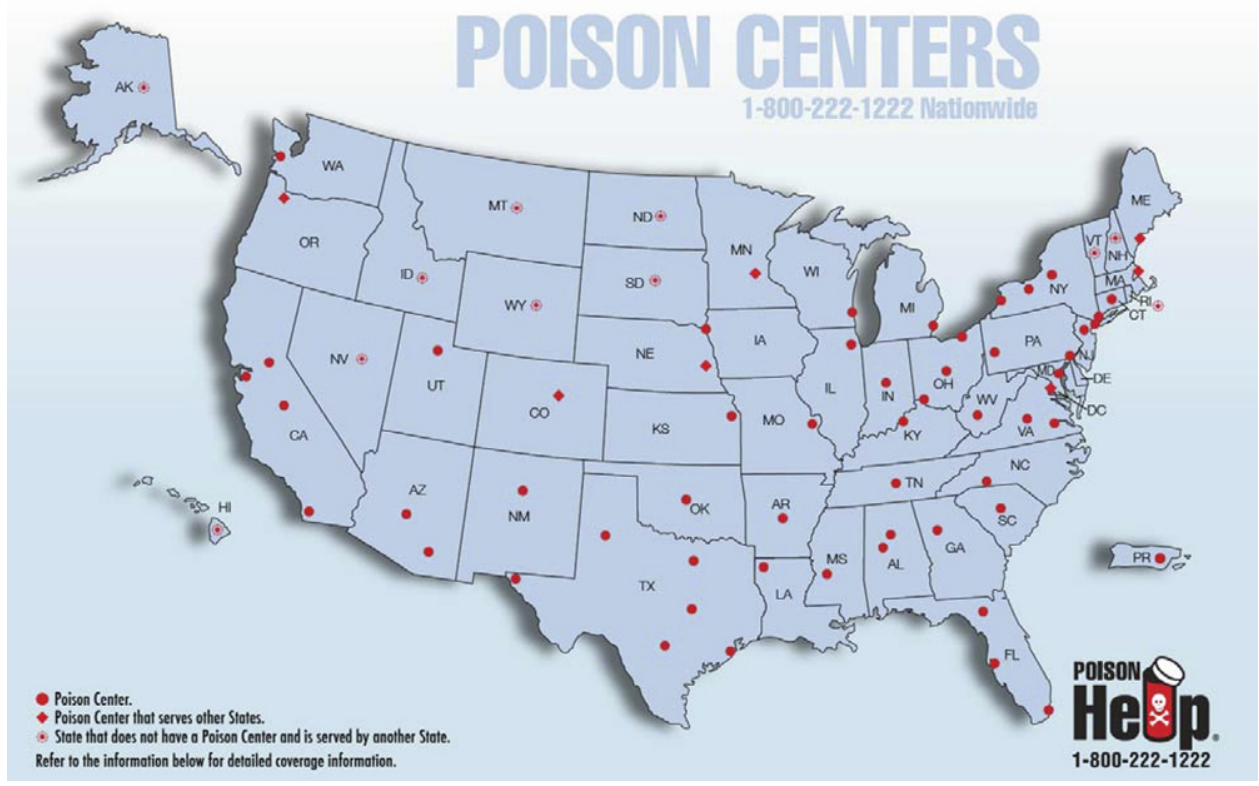

Figure 2. Distribution of poison centers in the United States.

Table. Surveillance outbreak tracking by American Association of Poison Control Centers National Poison Data System, 2003 to 2011.

\begin{tabular}{|c|c|c|c|}
\hline Date & Location & Substances & Summary \\
\hline April 2003 & New Sweden, Maine & Arsenic-contaminated coffee & $\begin{array}{l}\text { Criminal event: Clinical effects outliers detected } \\
\text { nationally after church function attendees } \\
\text { ingested arsenic-contaminated coffee }{ }^{7}\end{array}$ \\
\hline August 2003 & Northeast United States & Contaminated water & $\begin{array}{l}\text { Northeast power blackout: Increase in } \\
\text { contaminated water exposures detected }\end{array}$ \\
\hline January-April 2005 & $\begin{array}{l}\text { Connecticut, New Jersey, New } \\
\text { York, North Carolina, South } \\
\text { Carolina }\end{array}$ & $\begin{array}{l}\text { Heroin contaminated with } \\
\text { clenbuterol }\end{array}$ & $\begin{array}{l}\text { Outbreak of atypical effects of heroin abuse: } \\
\text { Tachycardia, hyperglycemia, palpitations, and } \\
\text { hypokalemia }^{8}\end{array}$ \\
\hline $\begin{array}{l}\text { August } 2005 \text { and } \\
\text { September } 2005\end{array}$ & Gulf Coast States & $\begin{array}{l}\text { Carbon monoxide, snake bite, food- } \\
\text { borne illness, water } \\
\text { contamination, and gasoline } \\
\text { siphoning }\end{array}$ & $\begin{array}{l}\text { Hurricanes Katrina and Rita: Daily reports } \\
\text { generated on substances of interest to CDC } \\
\text { and AAPCC }\end{array}$ \\
\hline September 2006 & National & $\begin{array}{l}\text { Case clusters reported from } 26 \\
\text { states }^{4}\end{array}$ & $\begin{array}{l}\text { Fresh spinach contaminated with } E \text { coli } 0157 \text { : } \\
\text { H7c: NPDS clearly showed the exposure } \\
\text { pattern. }\end{array}$ \\
\hline February 2007 & National & $\begin{array}{l}\text { Peanut butter contaminated with } \\
\text { Salmonella Tennessee }\end{array}$ & $\begin{array}{l}\text { Peanut butter contaminated with S Tennessee: } \\
\text { Cases initially reported in August } 2006 \text {. By } \\
\text { May } 22,2007 \text {, a total of } 628 \text { cases from } 47 \\
\text { states were documented. }{ }^{10}\end{array}$ \\
\hline March 2008 & National & $\begin{array}{l}\text { Increased selenium and chromium } \\
\text { levels }\end{array}$ & $\begin{array}{l}\text { Total body formula: NPDS used by CDC and the } \\
\text { Food and Drug Administration to track the } \\
\text { outbreak }\end{array}$ \\
\hline April 2009 & National & H1N1 influenza & $\begin{array}{l}\text { World Health Organization declared } 2009 \text { H1N1 } \\
\text { outbreak a public health emergency }\end{array}$ \\
\hline $\begin{array}{l}\text { March } 2009 \text { to May } \\
2010\end{array}$ & National & $\begin{array}{l}\text { Cocaine contaminated with } \\
\text { levamisole }\end{array}$ & $\begin{array}{l}\text { Neutropenia associated with cocaine abuse. } \\
\text { Joint project of CDC and AAPCC identified } \\
\text { cocaine-related cytopenia. }{ }^{11}\end{array}$ \\
\hline April 2010 & Gulf Coast & Oil & $\begin{array}{l}\text { Gulf oil spill: Poison center data used by } \\
\text { government agencies for situational } \\
\text { awareness }\end{array}$ \\
\hline March 2011 & Japan & Radiation release & $\begin{array}{l}\text { Japanese earthquake and tsunami: Poison } \\
\text { centers operated as call centers for } \\
\text { questions and exposures }\end{array}$ \\
\hline
\end{tabular}

AAPCC, American Association of Poison Control Centers; NPDS, National Poison Data System. 
explain events that had already transpired rather than inform containment efforts for an evolving event. This might allow improvement of response for the next incident but didn't help with the current incident. Real-time data such as those from the National Poison Data System are needed to quickly intervene and alter the course of mass events as they unfold.

Poison center data are often used to understand mass poisoning events, but the call center component of a poison center is overlooked. Poison center data are based on an individual interaction of a caller with skilled medical personnel. This function allows a poison center to change the course of events, in addition to collecting information. Poison centers can effectively inform callers in 2 ways. First, about half of the calls involve an exposure: the patient has been exposed in some manner to a potential toxin. In these cases, the poison center specialist provides patient-tailored recommendations. In more than $85 \%$ of these cases, the patient's care is complete at home; no EMS activation or ED visit is needed.

Second, the remaining calls received by poison centers are information calls: questions about an event, but no specific individual is known to have been exposed. For these individuals, standardized information from a reliable source such as the health department can be distributed directly to the recipient. For example, contaminated colonoscopes resulted in a Las Vegas, NV, epidemic of infectious hepatitis in 2008. The poison center was able to initiate a response system within hours that ultimately answered questions from more than 30,000 callers during a period of months. This information allows more targeted distribution of information directly to exposed individuals. Instead of desperately seeking care from uninformed sources, patients can be informed without a face-toface visit and then understand where, when, and how to access medical care. In many cases, no visit is needed. In others, it is important to go the correct place (ie, where antibiotics are being distributed in a mass casualty) at the right time. This system avoids innumerable calls and unneeded health care visits as patients try to understand their options.

\section{NEXT STOP, EXTINCTION?}

You might think that a large established system with a proven track record of success in both public health intervention and reducing health care expense would have adequate and stable funding. Unfortunately, the federal budget crisis of 2011 created yet another challenge for poison centers. The United States has often underfunded proven cost-effective public health interventions; poison centers are another fine example of underfunding. Financial support of a poison center is generally a patchwork affair involving the state budget, university or hospital in-kind support, charitable giving, and federal funding. Poison centers receive $15 \%$ to $20 \%$ of their operating support from the US government (currently the Poison Center Support, Enhancement and Awareness Act of 2008 [P.L. 110-377]). ${ }^{13}$ In the 2011 federal budget crisis, the US House of Representatives advanced legislation that eliminated $93 \%$ of federal funding for poison centers. After a vigorous campaign and inspiring grass root support throughout the United States, the final number for poison centers was a $25 \%$ reduction in the federal funding component.

Discussions with congressional leaders indicate that even more serious concerns are in our future. Despite agreement that poison centers are effective and allow US government programs such as Medicaid and Medicare to avoid more than $\$ 1$ billion a year in unnecessary health care costs, an estimate affirmed by several research studies and independent organizations such as the Institute of Medicine, further cuts have already been proposed by the House for 2012. The problem seems to be that such programs are not politically convenient at this time. They are an expense to be cut, even if the net effect will be to increase federal health care spending by billions of dollars. Poison center effectiveness is appreciated, but "someone else" should pay for them.

Organizations such as the American College of Emergency Physicians and the Institute of Medicine have openly endorsed the effectiveness and need for poison centers in the United States. ${ }^{5,14}$ These centers have a 50 -year history of success and cost-effectiveness, but can they survive blind budget cutting? The American Association of Poison Control Centers will continue to educate the public and legislators about our secret life: providing crucial information to sentinel surveillance programs for $\mathrm{CDC}$ and serving as a key local, state, regional, and national resource in mass casualty events such as $\mathrm{H} 1 \mathrm{~N} 1$ influenza. These activities will occur while we continue our daily efforts to reduce the toll of poisoning patient by patient. The millions of people who rely on poison centers each year reveal the demand for a system of medical call centers that can provide real-time surveillance throughout the United States. Poison centers are ready to serve.

\section{Supervising editor: Kathy J. Rinnert, MD, MPH}

Dr. Rinnert was the supervising editor on this article. Dr. Dart did not participate in the editorial review or decision to publish this article.

Funding and support: By Annals policy, all authors are required to disclose any and all commercial, financial, and other relationships in any way related to the subject of this article as per ICMJE conflict of interest guidelines (see www.icmje. org). Dr. Dart is the current elected president of American Association of Poison Control Centers.

Address for correspondence: Richard C. Dart, MD, PhD, E-mail rdart@rmpdc.org.

\section{REFERENCES}

1. Institute of Medicine, Committee on Poison Prevention and Control, Board on Health Promotion and Disease Prevention. Chapter 1: Introduction. In: Forging a Poison Prevention and Control System. Washington, DC: National Academies Press; 2004:24.

2. O'Brien C. Pediatric poisoning fatalities from 1972 through 2007. United States Consumer Product Safety Commission Report. August 2010. Available at: http://www.cpsc.gov/library/foia/ foia10/os/pppa2010.pdf. Accessed September 10, 2011. 
3. Veltri L. The 1983 report of the American Association of Poison Control Centers. Available at: http://www.aapcc.org/archive/Annual\% 20Reports/83Report/83Sect1.pdf. Accessed September 10, 2011.

4. Bronstein AC, Spyker DA, Cantilena LR Jr, et al. 2009 Annual report of the American Association of Poison Control Centers' National Poison Data System (NPDS): 27th annual report. Clin Toxicol. 2010;48:979-1178.

5. Institute of Medicine, Committee on Poison Prevention and Control, Board on Health Promotion and Disease Prevention. Chapter 6: Current costs, funding and organizational structures. In: Forging a Poison Prevention and Control System. Washington, DC: National Academies Press; 2004:136-175.

6. Miller TR, Lestina DC. Cost of poisoning in the United States and savings from poison control centers: a benefit-cost analysis. Ann Emerg Med. 1997;29:239-245.

7. Watson WA, Litovitz TL, Klein-Schwartz W, et al. 2003 Annual report of the American Association of Poison Control Centers Toxic Exposure Surveillance System. Available at: http://www.aapcc.org/dnn/ portals/0/ajem\%20-\%20aapcc\%20annual\%20report\%202003.pdf. Accessed October 20, 2011.

8. Hoffman RS, Kirrane BM, Marcus SN, et al. A descriptive study of an outbreak of clenbuterol-containing heroin. Ann Emerg Med. 2008;52:548-553.
9. Centers for Disease Control and Prevention. Ongoing multistate outbreak of Escherichia coli serotype 0157:H7 infections associated with consumption of fresh spinach-United States, September 2006. MMWR Morb Mortal Wkly Rep. 2006;55:1045-1046.

10. Centers for Disease Control and Prevention. Multistate outbreak of salmonella infections associated with peanut butter and peanut butter-containing products-United States, 2008-2009. MMWR Morb Mortal Wkly Rep. 2009;58:85-90.

11. Centers for Disease Control and Prevention. Agranulocytosis associated with cocaine use-four states, March 2008-November 2009. MMWR Morb Mortal Wkly Rep. 2009;58: 1381-1385.

12. Wolkin AF, Martin CA, Law RK, et al. Using poison center data for national public health surveillance for chemical and poison exposure and associated illness. Ann Emerg Med. 2012;59:56-61.

13. Public Law 110-377-Poison Center Support, Enhancement, and Awareness Act of 2008. Available at: http://www.gpo.gov/fdsys/ pkg/PLAW-110publ377/content-detail.html. Accessed October 20, 2011.

14. American College of Emergency Physicians. Role of poison centers in emergency health care, preparedness and response. Available at: http://www.acep.org/Content.aspx?id=53474. Accessed October 20, 2011.

\section{CORRECTION NOTICE}

In the article by Zhu et al, "Implications of Conducting Trend Analyses of Emergency Department Visits Using Publicly Released Masked Design Variables," published June 2011, Volume 57, Issue 6, pages 683-687, an error was noted. The error was caused by failing to impose a normal reference distribution for the confidence limits within SAS NLMIXED. ${ }^{1}$ The program defaults to a $t$ distribution with degrees of freedom equal to number of observations minus number of estimated parameters. A normal reference distribution can be imposed by specifying $d f=500$ to override the default. On doing so, in the second sentence of the "Results" in the abstract, the 95\% confidence interval (Cl) for the annual increase of overall emergency department (ED) visit counts for unmasked data should be 0.505 to 3.440 million instead of 0.145 to 3.800 ; in the third sentence of the "Results" in the abstract, the $95 \% \mathrm{Cl}$ for the annual change for masked data should be 0.221 to 3.733 million instead of -0.210 to 4.164 . The last row of Table 2 and Table 3 should be updated as follows:

Table 2. Estimated linear trend in national ED visit count, based on masked and unmasked data, 1999 to 2006, United States.

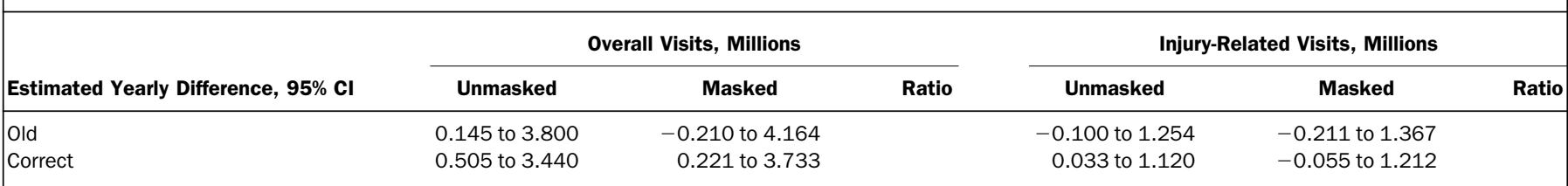

Table 3. Estimated linear trend in national ED visit rate, based on masked and unmasked data, 1999 to 2006, United States.

\begin{tabular}{|c|c|c|c|c|c|c|}
\hline \multirow[b]{2}{*}{ Estimated Yearly Difference, 95\% CI } & \multicolumn{3}{|c|}{ Overall Rate (per 100) } & \multicolumn{3}{|c|}{ Injury-Related Rate (per 100) } \\
\hline & Unmasked & Masked & Ratio & Unmasked & Masked & Ratio \\
\hline Old & -0.392 to 0.898 & -0.521 to 1.023 & & -0.195 to 0.283 & -0.236 to 0.322 & \\
\hline Correct & -0.265 to 0.771 & -0.369 to 0.871 & & -0.148 to 0.236 & -0.181 to 0.267 & \\
\hline
\end{tabular}

In Appendix: E1, b) SAS program for weighted least squares linear regression, the degrees of freedom should be 500 instead of 6 .

\section{REFERENCE}

1. Zhu M, Chu H, Greenland S. Biased standard errors from complex survey analysis: an example from applying ordinary least squares to the National Hospital Ambulatory Medical Care Survey. Ann Epidemiol. 2011;21:830-834. 